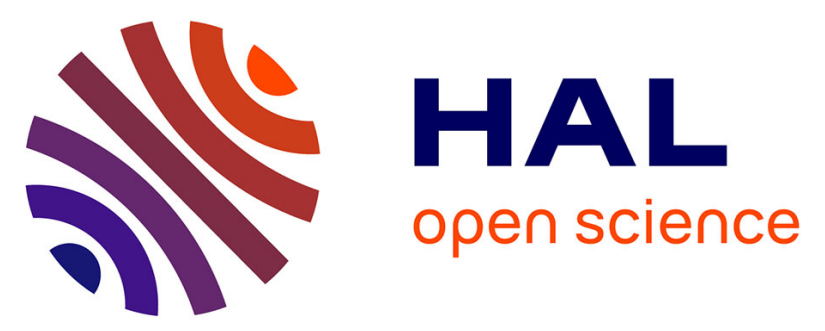

\title{
Electromagnetic ELF radiation from earthquake regions as observed by low-altitude satellites
}

\author{
O. Serebryakova, S. Bilichenko, V. Chmyrev, Michel Parrot, Jean-Louis \\ Rauch, François Lefeuvre, O. A Pokhotelov
}

\section{- To cite this version:}

O. Serebryakova, S. Bilichenko, V. Chmyrev, Michel Parrot, Jean-Louis Rauch, et al.. Electromagnetic ELF radiation from earthquake regions as observed by low-altitude satellites. Geophysical Research Letters, 1992, 19 (2), pp.91-94. 10.1029/91GL02775 . insu-03209896

\section{HAL Id: insu-03209896 https://hal-insu.archives-ouvertes.fr/insu-03209896}

Submitted on 27 Apr 2021

HAL is a multi-disciplinary open access archive for the deposit and dissemination of scientific research documents, whether they are published or not. The documents may come from teaching and research institutions in France or abroad, or from public or private research centers.
L'archive ouverte pluridisciplinaire HAL, est destinée au dépôt et à la diffusion de documents scientifiques de niveau recherche, publiés ou non, émanant des établissements d'enseignement et de recherche français ou étrangers, des laboratoires publics ou privés. 


\title{
ELECTROMAGNETIC ELF RADIATION FROM EARTHOUAKE REGIONS AS OBSERVED BY LOW-ALTITUDE SATELLITES
}

\author{
O.N. Serebryakova ${ }^{1}$ S.V. Bilichenko ${ }^{1}$, V.M. Chmyrev ${ }^{1}$, M. Parrot ${ }^{2}$, \\ J.L. Rauch ${ }^{2}$, F. Lefeuvre, and O.A. Pokhotelov ${ }^{3}$
}

Abstract. Seismo-Electromagnetic (SEM) waves observed by low-altitude satellites passing over seismic regions were studied. The data of the COSMOS-1809 satellite were analysed over the earthquake region in Armenia during the period from January 20 to February 17, 1989. Intense EM radiation at frequencies below $450 \mathrm{~Hz}$ was observed at the L-shells of the earthquake, during 12 orbits out of the 13 that passed within $6^{\circ}$ in longitude from the epicenter, and during 1 out of 6 in the range of $6^{\circ}-8^{\circ}$ longitude away from this region. The other orbits, which passed $10^{\circ}-12^{\circ}$ from the epicentre, showed no effect. To complete this study, we used the emissions observed by another low-altitude satellite (AUREOL-3). It is shown that during the event the seismic region is permanently radiating; the intensity and the envelope shape of the wave depend on its time relatively to the time of the earthquake. Their frequency spectra are compared to the average spectrum recorded in the same geomagnetic regions. Similar wave intensities and spectral distributions were observed on the two satellites during the seismic periods.

\section{Introduction}

Several reports have been published on the observations on ground of SEM emissions [Gokhberg et al., 1982; Warwick et al., 1982; Fraser-Smith et al., 1990; Fujinawa and Takahashi, 1990]. Descriptions of mechanisms that might produce SEM emissions are available in the literature. Two main mechanisms are generally invoked: the first concems direct-wave production by compression of rocks near the focal point [Ogawa et al., 1985; Cress et al., 1987], whereas the second is related to a redistribution of the electric charges in the Earth's atmospheric system, which produces electrical discharges [Gokhberg et al., 1988; Enomoto and Hashimoto, 1990]. Perturbations of the ionosphere are also known to occur, and SEM emissions have already been observed from satellites [Gokhberg et al., 1983; Larkina et al., 1983; Parrot and Lefeuvre, 1985; Chmyrev et al., 1989; Parrot and Mogilevsky, 1989; Parrot, 1990a; Bilichenko et al., 1990].

The aim of this study was to determine the zone in the ionosphere over an earthquake region where SEM waves can be observed and to find their characteristic time scale. The intensity and the frequency dependence of the signals are discussed. For this purpose we carried out a special program of observations onboard the COSMOS-1809 satellite from

\footnotetext{
${ }^{1}$ Institute of Terrestrial Magnetism, Ionosphere and Radio Wave Propagation

${ }^{2}$ Laboratoire de Physique et Chimie de l'Environnement, CNRS

${ }^{3}$ Institute of Physics of the Earth
}

Copyright 1992 by the American Geophysical Union.
January 20 to February 17,1989 , and analysed the data over the epicentral region in Armenia. The region and the time interval was chosen to study the possible ionospheric effects of strong aftershocks of crucial earthquake in Spitak $\left(40.7^{\circ} \mathrm{N}\right.$, 44.0 $0^{\circ}$; December 7, 1988, $M=6.7$ ). These data are compared with the data obtained from the AUREOL-3 satellite.

\section{Experimental results}

The COSMOS-1809 satellite was operating in near-circular orbits $\left(970 \mathrm{~km}, \mathrm{i}=82.5^{\circ}\right)$. ELF/VLF measurements were made with a 5-channel parallel-spectrum analyzer, both in the electric $\left(E_{x}\right)$ and the magnetic $\left(B_{y}\right)$ fields, for which the $X$ and $Y$ axes were in a horizontal plane, being, repectively, North-South and East-West. The central frequencies of the analyzer were $F_{0}=140,450,800,4500$ and $15000 \mathrm{~Hz}$, the filter bandwidth $d F=F_{0} / 6$ and the sampling rate $0.39 \mathrm{~Hz}$.

According to Arefyev et al. (1989), during the period from January 20 to February 17, 1989, 729 aftershocks with energetic class $5.5 \leq \mathrm{K} \leq 12.0$ were registered within the zone $40.5^{\circ} \leq$ Lat. $\leq 41.5^{\circ}$ and $43.5^{\circ} \leq$ Long. $\leq 44.5^{\circ}$. The distribution of these aftershocks with energetic class is shown in Figure 1A. To characterize the energy of the seismic processes, we represented in Figure 1B the logarithm of

$$
E=\sum_{i=1}^{R} 10^{K_{i}}
$$

where $n$ is a number of aftershocks within considered 3 hour intervals and $K_{i}$ is an energetic class of aftershocks. The asterisks mark the periods of observation onboard the COSMOS-1809 satellite over the Spitak zone.

For analysis we selected the data from 24 orbits: 8 of them passing within $3^{\circ}$ in longitude to the west of the epicentral region, 5 being between $4^{\circ}$ and $6^{\circ}$ to the east of this region, 6 other orbits were between $6^{\circ}$ and $8^{\circ}$ west and 5 more from $10^{\circ}$ to $12^{\circ}$ east of the epicentre. Parts of these orbits in geographic coordinates are shown in Figure 2A. The dashed lines indicate the location where anomalous radiation (see below) was observed. The asterisk marks the location of epicentral region, and the solid line corresponds to the L-shell of its projection at an altitude of $100 \mathrm{~km}(\mathrm{~L}=1.42)$.

An example of the ELF intensity for the channels 140 and $450 \mathrm{~Hz}$ over the earthquake region is shown in Figure 2B. It is seen that an intense SEM emission of about $10 \mathrm{~m} \gamma$ around $F_{0}=140 \mathrm{~Hz}$ was observed from $33.7^{\circ}$ up to $30^{\circ}$ in latitude. Enhancement of noise was also observed in the channel of $450 \mathrm{~Hz}$, although its intensity did not exceed $3 \mathrm{~m} \gamma$. In both channels the maximum occurred at the geomagnetic latitude of the epicentre $(L=1.42)$. At higher frequencies no emissions were observed. In this example of January 20 , 1989, the ELF emission was registered 2.5 hours before the earthquake, with the energetic class $K=10.5$, at the distance $\sim 1.5^{\circ}$ to the west of the epicentre. A similar example (January 23, 1989) is presented in Figure 2C. In this case, as 
in the previous one, SEM emissions at frequencies $\sim 140 \mathrm{~Hz}$ were observed within a zone of about $4^{\circ}$ length in latitude, with a maximum of intensity in the magnetic-field tube of the earthquake region $(L \sim 1.42)$. This event was registered at a distance of $\sim 1.5^{\circ}$ in longitude to the west of the epicentre approximately 10 minutes before a shock with $K=9.0$ and about 2.9 hours before a shock with $\mathrm{K}=10.7$. Other similar characteristics that were observed within 3-hour intervals before the main shocks are the quasi-regular modulation of the wave intensity. The example shown in Figure 2D illustrates the observation over the same region during the long series of weaker and numerous shocks.

The examples presented above were obtained along the orbits that crossed the L-shell of the earthquake region not more than $3^{\circ}$ away in longitude from the epicenter. All 8 passages within this $3^{\circ}$-interval recorded emissions similar to those shown in Figures 2B to 2D. Similar radiation patterns were observed during 4 of 5 orbits that passed from $4^{\circ}$ to $6^{\circ}$ away from longitude of the epicentre, but only in one case of 6 where the satellite was between $6^{\circ}$ and $8^{\circ}$ distant. No effects were seen during the 5 orbits that passed at a distance from $10^{\circ}$ to $12^{\circ}$ in longitude. It should be noted that in all cases when ELF emissions were observed over the Spitak region, only normal background noise was observed at the same L-shells during the following and preceding orbits.

The same phenomenon was observed on the VLF experiment ARCAD-3 [Berthelier et al., 1982] of the satellite AUREOL-3 $\left(a=2000 \mathrm{~km}, \mathrm{p}=400 \mathrm{~km}, \mathrm{i}=82.5^{\circ}\right)$. Waveform data in the band $5-1500 \mathrm{~Hz}$ were recorded at Suggadeira (Japan) when the satellite was over an earthquake in preparation (M=4.9, April 9, $1982,23.41 \mathrm{UT}, 41.38^{\circ} \mathrm{N}$, $\left.142.14^{\circ} \mathrm{E}\right)$. A part of the AUREOL-3 orbit is plotted in Figure $3 \mathrm{~A}$. The star indicates the epicentre of the earthquake, which occurred roughly 5 hours after the pass of the satellite. A spectral analysis shows the same turbulent power spectra as
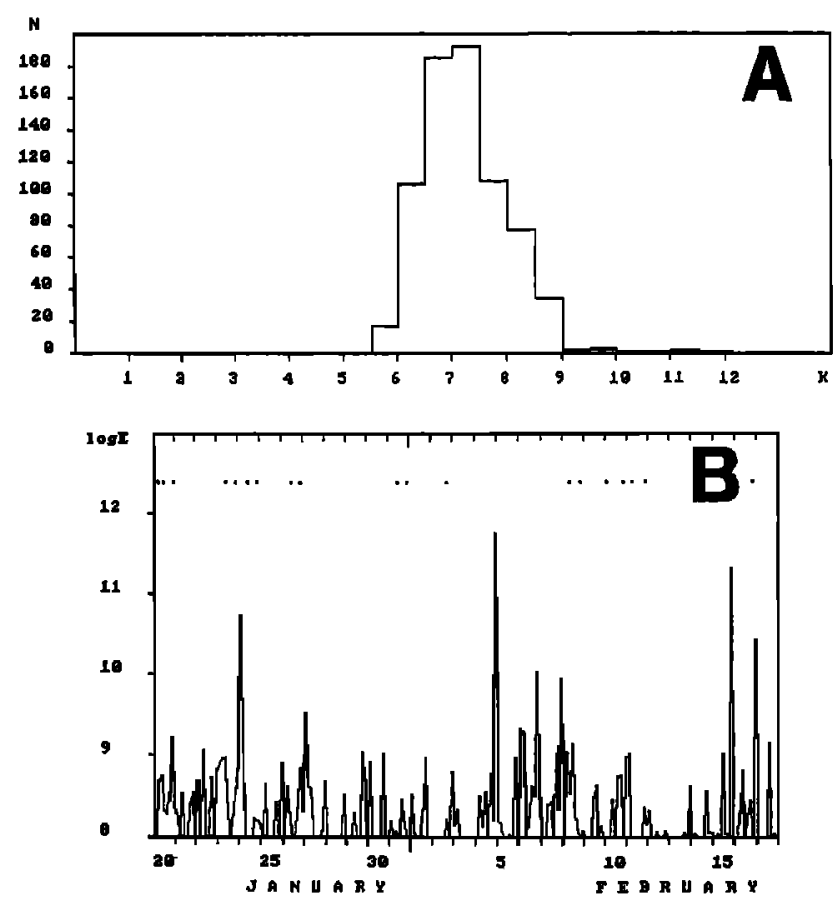

Fig. 1. A.- Number of aftershocks as a function of energetic class. B.- Characterization of seismic activity (see text). The asterisks show when the satellite was operating over Spitak. those observed on COSMOS-1809. As a comparison, the time variation of the signals on the magnetic component $B_{x}$ in the $140-240 \mathrm{~Hz}$ band and in the $400-500 \mathrm{~Hz}$ band was plotted, respectively, in Figures 3B and C. Regular blanks are due to the on-board calibrations that were removed from the data. As in the COSMOS-1809 cases, an increase is observed at the lowest frequencies (Figure 3B), when the satellite was in the magnetic-field tube of the earthquake region $(L \sim 1.34)$. The increase is slightly seen in the band $400-500 \mathrm{~Hz}$ and disappears at higher frequencies (Figure 3C). However, looking at the filterbank data it can be seen that the noise level was high in the $15 \mathrm{kHz}$ filter. It is thus likely that two different wave phenomena occurred over the seismic region, but, it is difficult to know if they were related or not.
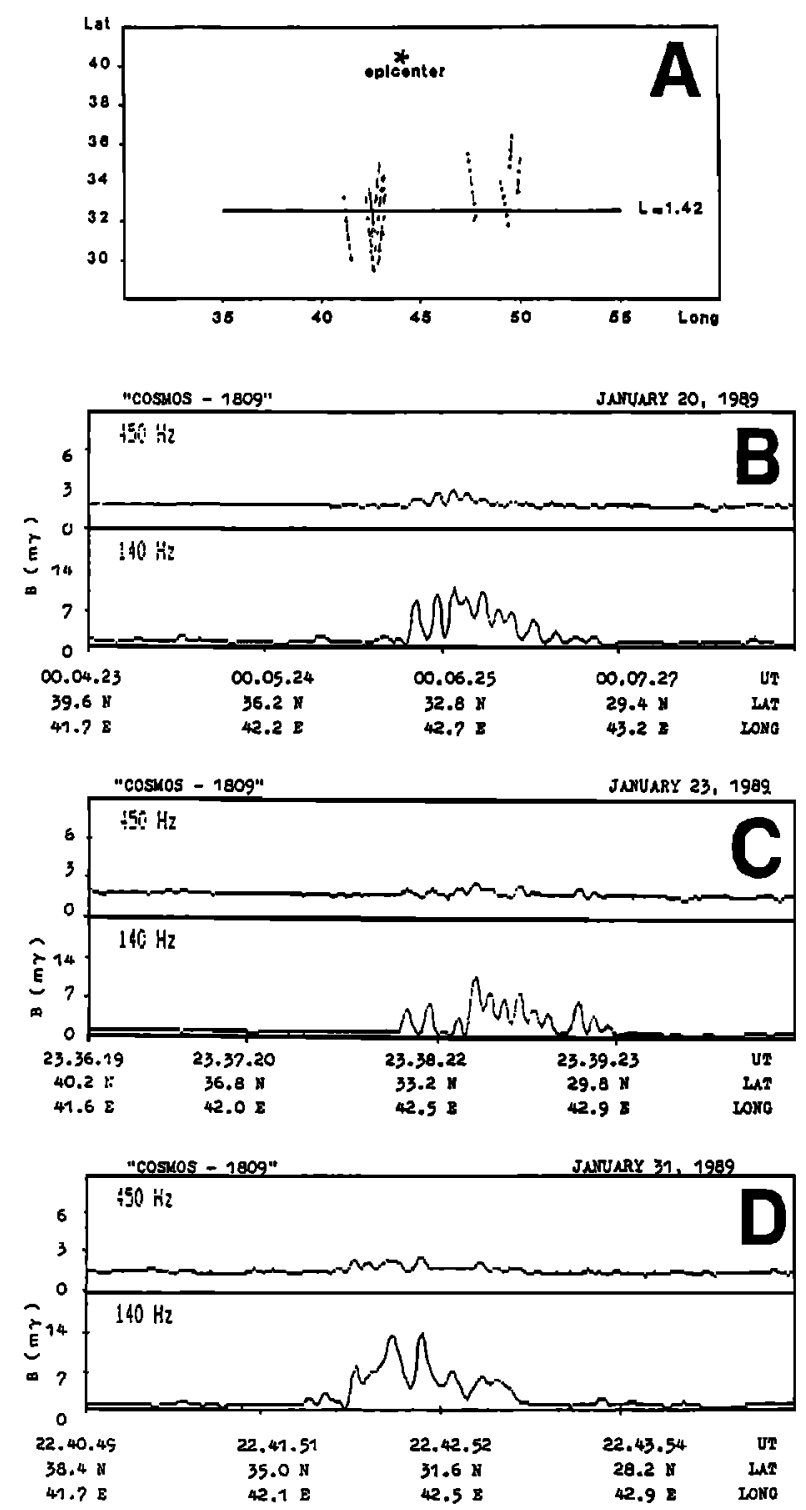

Fig. 2. Observations made by COSMOS-1809. A.- Location of the epicentre and orbits of the satellite where emissions are observed. B.- Observations in two frequency bands (140 and $450 \mathrm{~Hz}) 2.5$ hours before an earthquake. The time UT, the latitude and longitude are indicated. C.-Observations recorded 10 minutes and 2.9 hours before two shocks. D.- Observations during the long series of weaker and numerous earthquakes. 


\section{Discussion}

The observations of ELF/VLF waves onboard COSMOS1809 over the Spitak region show that SEM emissions at frequencies below $450 \mathrm{~Hz}$ were regularly observed around the L-shell of the earthquake, when the satellite passed within $6^{\circ}$ in longitude from the epicentre. The fact that such emissions were never observed during the orbits located more than $10^{\circ}$ away from the earthquake, and the right magnetic conjugacy between the registration zone and the epicenter, support the conclusion that these emissions are of seismic origin. Principally, low-altitude emissions at $100-500 \mathrm{~Hz}$ can be stimulated in the ionosphere by powerful ground-based VLF transmitter (Chmyrev et al., 1990; Parrot, 1990b) or radiated from power lines harmonic radiations (PLHR) of $50 \mathrm{~Hz}$. However there are no VLF transmitters where we collected the data for this study. The nearest VLF transmitter (Krasnodar: $45^{\circ} \mathrm{N}, 38^{\circ} \mathrm{E}$ ) was not seen in the channel $15 \mathrm{kHz}$ at the fragments of orbits shown in Figure 2A. Concerning
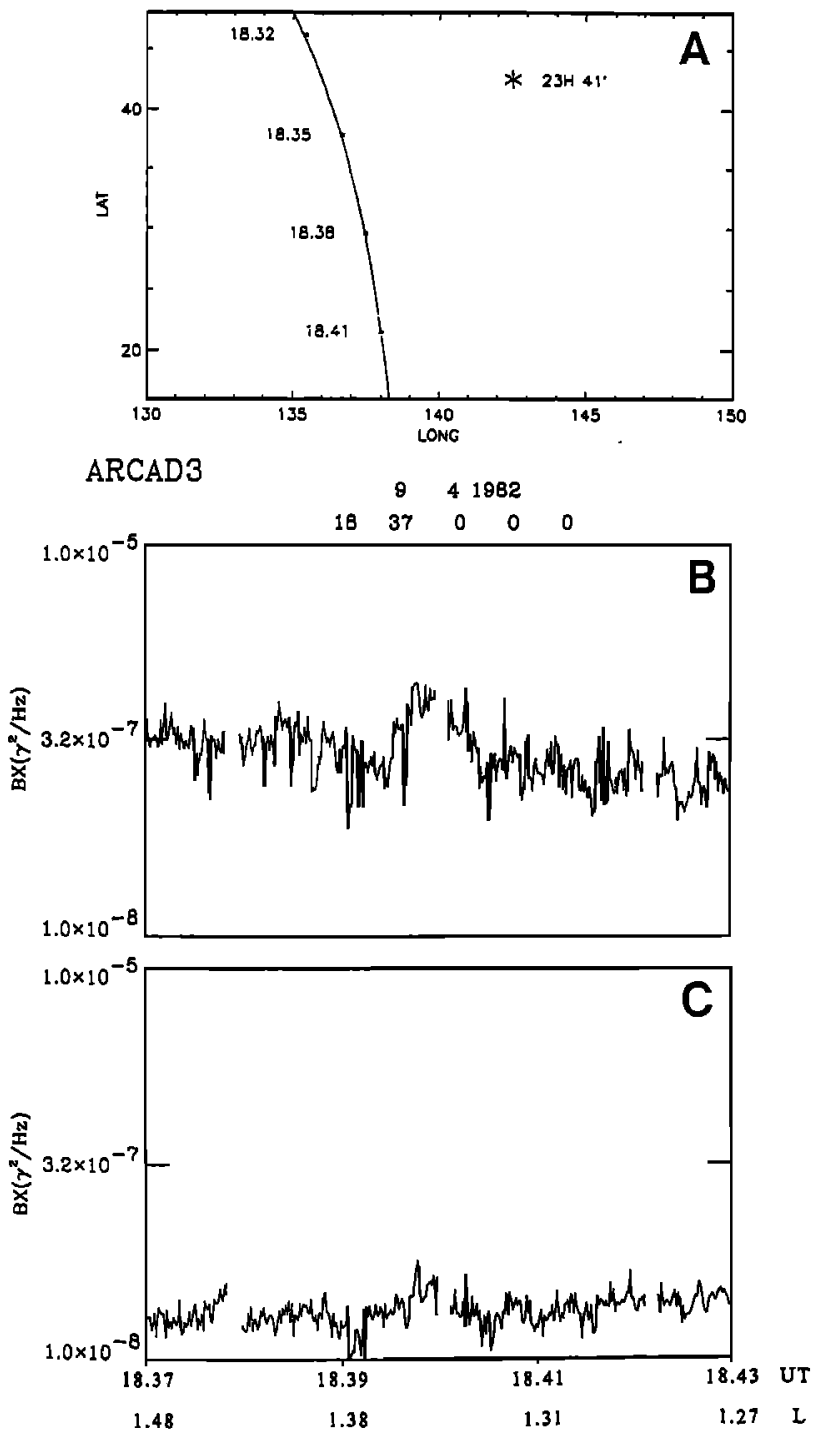

Fig. 3. Observations made by AUREOL-3. A.- Orbit of the satellite with time as a function of the latitude and longitude. B.- Average amplitude recorded in the frequency band 140$240 \mathrm{~Hz}$ as a function of the time UT and the $\mathrm{L}$ value. C.Same as B but in the frequency band $400-500 \mathrm{~Hz}$. the PLHR, its intensity at an altitude about $100 \mathrm{~km}$ is much lower than the intensity we observed. No other sources of ELF radiation (either natural or man-made) in this narrow ( $\left.6^{\circ}\right)$ low-latitude region are known to the authors.

An important feature of the wave phenomenon observed on COSMOS-1809 is the modulation of the wave intensity. This intensity at $140 \mathrm{~Hz}$ was modulated with a period about $5 \mathrm{sec}$. during 4 passages from the 8 within the $3^{\circ}$-interval (January 20 and 23, February 11 and 16). Three of these 4 events were registered less than 3 hours before the earthquakes with $\mathrm{K}=$ $10.5,10.7$ and 10.4. It must be noted that during the observations less than one percent of the earthquakes had an energetic class $\mathrm{K}>10$ (Figure 1A). So we suggest that this modulation can characterize the preparation processes of strong earthquakes. Two explanations can be considered: an interaction of ELF and VLF wave processes in the source region in the Earth, or, a formation of strong field-aligned plasma density inhomogeneities in the ionosphere over the earthquake region. Such a modulation is less clear from the ARCAD-3 data. If such a modulation was to be a constant feature, it could be interesting for the forecasting of earthquakes. Since ELF emissions were registered practically during each of the passes at less than $6^{\circ}$ of the earthquake region, we can consider that this region was permanently radiating during the active period. The characteristics of the radiation depend on the time difference between the observations and the actual onset of the earthquakes.

Different observations on COSMOS-1809 and AUREOL-3 of SEM waves have been combined to identify a powerspectrum signature (Figure 4). The upper panel (E) is related to the electric amplitude and the lower (B) to the magnetic one. As a reference, the solid lines represent the average amplitude recorded by AUREOL-3 all around the Earth at invariant latitudes less than $30^{\circ}$. The ARCAD-3 data of this paper (Figure 3) are plotted as dash-dot lines at 19.39.49 UT. The long-dash line in Figure $4 B$ represents the average amplitude observed during the Armenian earthquakes, completed (at low frequency) by Bilichenko et al. (1990). Other examples from AUREOL-3 measurements are shown as a dashed line (Parrot and Mogilevsky, 1989) and as a dotted line (Parrot, 1990a). Figure 4 illustrates two different points: first, the power of the waves associated with earthquakes is higher than the power of the natural noises at those latitudes;
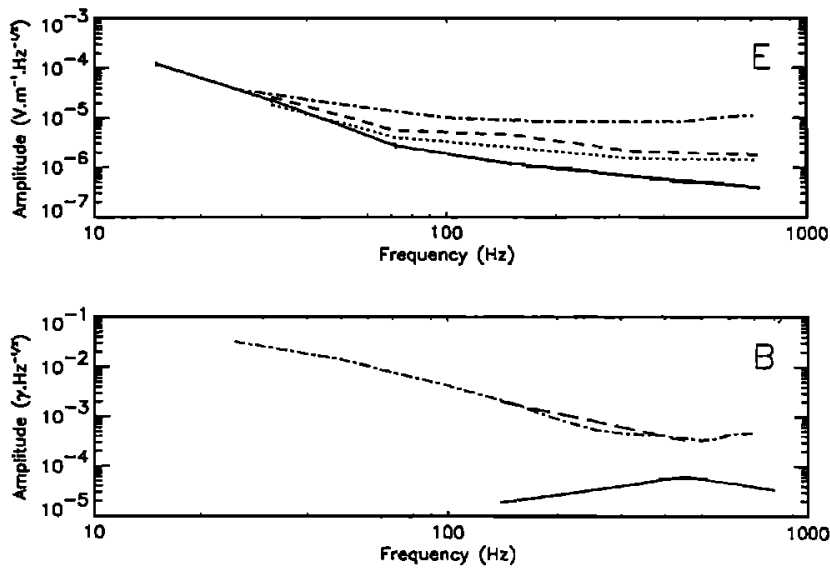

Fig. 4. Amplitudes, as a function of the frequency, of the electric (upper panel) and magnetic (lower panel) signals recorded by COSMOS-1809 and AUREOL-3 (see text). 
Serebryakova et al.: ELF radiation from earthquake regions

second, the amplitudes observed during different events by two different low-altitude satellites are very similar.

As a comparison, the amplitude (B) of the signal received on the COSMOS-1809 magnetic components over Spitak has been expressed in terms of the amplitude (E) of the electric components. We assume that $E$ and $B$ are related through the equation: $E=c B / n$ with $c$ being the velocity of the light in vacuum and $n$ the refractive index. The observed plasma frequency being of the order of $1.2 \mathrm{MHz}$ and the electron gyrofrequency being about $780 \mathrm{kHz}$, we have estimated the n values for a medium with 50 to $80 \%$ of $\mathrm{H}^{+}$ions. We obtain values of about $2.10^{-4} \mathrm{~V} / \mathrm{m}$ at $10 \mathrm{~Hz}, 5.10^{-6} \mathrm{~V} / \mathrm{m}$ at $150 \mathrm{~Hz}$ and $10^{-6} \mathrm{~V} / \mathrm{m}$ at $450 \mathrm{~Hz}$, which are in perfect agreement with the electric measurements performed on AUREOL-3.

\section{Conclusion}

Measurements of ELF/VLF waves onboard the COSMOS-1809 satellite in the ionosphere, during the seismically-active period from January 20 to February 17, 1989 over the Spitak region, have shown that intense ELF radiation was generated in the zone of $6^{\circ}$ in longitude and $2^{\circ}-4^{\circ}$ in latitude around the earthquake. The intensity of this radiation was about $10 \mathrm{~m} \gamma$ at $140 \mathrm{~Hz}(\mathrm{dF}=25 \mathrm{~Hz})$ and about $3 \mathrm{~m} \gamma$ at $450 \mathrm{~Hz}(\mathrm{dF}=75 \mathrm{~Hz})$. The intensity of the emissions observed less than 3 hours before earthquakes had a quasi-periodic modulation. The amplitude and the frequency dependence of the emissions recorded by different satellites are similar. However, due to the limited frequency band observed by the satellites, only parts of the spectrum radiated by an earthquake zone are known at the moment.

Acknowledgements. The ELF/VLF experiment of the COSMOS-1809 satellite was prepared under leadership of O.A. Molchanov and Ya.P. Sobolev. The authors thank M.D. Fligel for planning of satellite operations. The AUREOL-3 program was undertaken jointly by CNES in France, and by INTERCOSMOS and IKI in the USSR. We thank J.J. Berthelier, who is the principal investigator of the VLF experiment, for the use of the data, and Yu I. Galperin who drew our attention to the Suggadeira data.

\section{References}

Arefyev S. S. et al., Previous results of Soviet-French seismic observations at the Spitak earthquake region on December 7, 1988, The founds of Institute of Physics of the Earth, USSR Academy of Science, Moscow, 1989.

Berthelier J.J., F. Lefeuvre, M.M. Mogilevsky, O.A. Molchanov, Yu.I.Galperin, J.F. Karczewski, R. Ney, G. Gogly, C. Guerin, M. Leveque, J.M. Moreau and F.X. Sene, Measurements of the VLF electric and magnetic components of waves and DC electric field on board the AUREOL-3 satellite: the TBF-ONCH experiment, Ann. Geophys., 38, 643, 1982.

Bilichenko S.V., A.S. Inchin, E.F. Kim, O.A. Pokhotelov, P.P. Puschaev, G.A. Stanev, A.V. Streltsov and V.M. Chmyrev, ELF response of the ionosphere on preearthquake processes. DAN USSR, 311, 1077, 1990.

Chmyrev V.M., N.V. Isaev, S.V. Bilichenko and G. Stanev, Observation by space-borne detectors of electric fields and hydromagnetic waves in the ionosphere over an earthquake centre, Phys. Earth Planet Inter., 57, 110 , 1989.
Chmyrev V.M., A.B. Draganov, Yu. N. Taranenko and D. Teodosiev, Acceleration of particles in the upper ionosphere and the magnetosphere due to decay interactions of whistlers, I, Physica Scripta, 43, 495, 1991.

Cress G.O., B.T. Brady and G.A. Rowell, Sources of electromagnetic radiation from fracture of rock samples in the laboratory, Geophys. Res. Lett., 14, 331, 1987.

Enomoto $Y$. and $H$. Hashimoto, Emission of charged particles from indentation fracture of rocks, Nature, 346, 641, 1990.

Fraser-Smith A.C., A. Bernardi, P.R. McGill, M.E. Ladd, R.A. Helliwell and O.G. Villard Jr., Low-frequency magnetic field measurements near the epicenter of the $\mathrm{M}_{2}$ 7.1 Loma Prieta earthquake, Geophys. Res. Lett., 17, $1465,1990$.

Fujinawa Y. and $\mathrm{K}$. Takahashi, Emission of electromagnetic radiation preceding the Ito seismic swarm of 1989 , Nature, 347, 376, 1990.

Gokhberg M.B., V.A. Morgounov, T. Yoshino and I. Tomizawa, Experimental measurement of electromagnetic emission possibly related to earthquakes in Japan, $J$. Geophys. Res., 87, 7824, 1982.

Gokhberg M.B., V.A. Pilipenko and O.A. Pokhotelov, Seismic precursors in the ionosphere, Izvestiya Earth Physics, 19, 762, 1983.

Gokhberg M.B., V.A. Morgounov and O.A. Pokhotelov, Seismic electromagnetic phenomena, Nauka, 169, 1988.

Larkina V.I., A.V. Nalivayko, N.I. Gershenzon, M.B. Gokhberg, V.A. Liperovskiy and S.L. Shalimov, Observation of VLF emissions, related with seismic activity, on the INTERCOSMOS-19 satellite, Geomagn. Aeron., 23, 684, 1983.

Ogawa T,, K. Oike and T. Miura, Electromagnetic radiations from rocks, J. Geophys. Res., 90, 6245, 1985.

Parrot M. and F. Lefeuvre, Correlation between GEOS VLF emissions and earthquakes, Ann. Geophys., 3, 737, 1985.

Parrot M. and M.M. Mogilevsky, VLF emissions associated with earthquakes and observed in the ionosphere and the magnetosphere, Phys. Earth Planet Inter., 57, 86, 1989.

Parrot M., Electromagnetic disturbances associated with earthquakes: an analysis of ground-based and satellite data, Journal of Scientific Exploration, 4, 203, 1990a.

Parrot M., World map of ELF/VLF emissions as observed by a low-orbiting satellite, Ann. Geophys., 8, 135, 1990b.

Warwick J.W., C. Stoker and T.R. Meyer, Radio emission associated with rock fracture: possible application to the great Chilean earthquake of May 22, 1960, J. Geophys. Res., 87, 2851, 1982.

S.V. Bilichenko, V.M. Chmyrev and O.N. Serebryakova, Institute of Terrestrial Magnetism, Ionosphere and Radio Wave Propagation, 142092 Troitsk, Moscow region, USSR.

F. Lefeuvre, M. Parrot and J.L. Rauch, LPCE/CNRS, 3A Avenue de la Recherche, 45071 Orleans cedex 2, France. O.A. Pokhotelov, Institute of Physics of the Earth, B. Gruzinskaya 10, Moscow 123810, USSR.

(Received: Mars 5, 1991;

Revised: September 10, 1991;

Accepted: October 28, 1991.) 